\title{
BURAWOY, Michael (2009). O marxismo encontra Bourdieu. Editora UNICAMP, Campinas.
}

\section{Juliana Vinuto Lima e Felipe Lários de Souza Monteiro*}

A obra $O$ marxismo encontra Bourdieu é fruto de seis conferências que Michael Burawoy, um dos principais teóricos marxistas contemporâneos e professor de sociologia na Universidade de Berkeley (EUA), proferiu no Havens Center de Wisconsin. Neste instigante trabalho, Burawoy estabelecerá "conversações imaginárias" entre Pierre Bourdieu e os teóricos marxistas preferidos do autor (além dele mesmo e do próprio Marx): Antonio Gramsci, Frantz Fanon, Simone de Beauvoir e Wright Mills. Burawoy justifica suas escolhas alegando que Bourdieu sempre demonstrou uma postura muito hostil em relação àqueles autores (com exceção de Mills) e criou, por meio dessas conferências, uma oportunidade para esses autores responderem às críticas de Bourdieu. 0 resultado é um minucioso estudo comparativo entre os mais diversos enfoques do marxismo e a obra de um dos mais influentes nomes da sociologia contemporânea: Pierre Bourdieu.

Analisando a presente obra de Burawoy, não demoramos para perceber algumas constantes, seja no que se refere ao retorno reiterado a certas temáticas, seja no estilo do autor. Em primeiro lugar, podemos afirmar que é nítida sua preocupação em analisar comparativamente o modo como cada um dos autores, Bourdieu e seus interlocutores, concebem a consciência dos grupos dominados. Teriam esses grupos (mulheres, o proletariado, minorias étnicas, entre outros) consciência de sua própria dominação? É possível existir bom senso dentro do senso comum? Qual o papel dos intelectuais ante a dominação? Outra constante é a comparação entre o escopo teórico de cada autor e seu engajamento político. Nesse sentido, o papel dos dados biográficos é de suma relevância em cada um dos capítulos-aulas que compõe o livro, recebendo espaço bastante significativo na obra.

\footnotetext{
* Graduandos em Ciências Sociais - USP.
} 
Nesses dois primeiros pontos, Burawoy terá em mente, a todo momento, a oposição gramsciana entre intelectual tradicional e intelectual orgânico, refletindo outra oposição, aquela entre teoria e prática, que também permeia a obra. Ao concluir a parte introdutória da obra que analisamos, Burawoy sintetiza quais são as perguntas que, cada um a sua maneira, todos os teóricos marxistas que ele põe em "diálogo imaginário" com Bourdieu faria ao sociólogo francês: "qual é a relação entre a teoria e prática? Qual a relação entre a sociologia e o mundo que ela revela?" (Burawoy, 2009, p. 20). Com base nesse questionamento, Burawoy expõe os dois paradoxos que Bourdieu ofereceria: por um lado, o fato de Bourdieu, a despeito de defender a independência do intelectual e o isolamento da sociologia do mundo social, ter sido o maior sociólogo público de sua geração: “Como então reconciliar a autonomia e o engajamento, a ciência e política?" (idem, ibidem) questiona-se Burawoy. Já no que diz respeito ao segundo paradoxo decorrente daquelas indagações, Burawoy nos diz:

Há classes dominantes que não possuem qualquer interesse em saber nada sobre sua própria dominação simbólica (embora pudessem compreendê-la); e há classes dominadas que não estão aptas a compreender sua submissão (embora isso pudesse interessar)" (idem, ibidem).

Esse é o ponto de fundo sobre o qual Burawoy desenvolverá os "encontros imaginários" entre Bourdieu e os intelectuais marxistas citados anteriormente. É importante ainda notar que em muitas oportunidades Burawoy fará o exercício de colocar vários autores em diálogo com Bourdieu numa mesma conferência, ou seja, ainda que cada capítulo se refira a um "encontro" específico com Bourdieu, esses autores serão continuamente resgatados por Burawoy em outros “diálogos”. Nessas conversas, poderemos observar também que são constantes as críticas, nem sempre amistosas, que Burawoy dirige a Bourdieu. No entanto, ainda que pontualmente, os elogios também aparecem, como a reiterada afirmação de que Bourdieu foi o maior sociólogo público de sua geração, além da afirmação de que Bourdieu "elaborou o que Marx deixara sem elaborar, a saber, as chamadas superestruturas sociais, com uma análise mais estrutural e funcional do que somente histórica" (idem, p. 16). 


\section{Bourdieu e Marx}

Como não poderia ser diferente, o livro em questão tem como primeiro capítulo um possível diálogo entre Bourdieu e o próprio Marx. E tais autores, mostra Burawoy, tem uma trajetória por vezes semelhantes: Marx e Bourdieu tiveram uma fase de acerto de contas com suas respectivas heranças filosóficas, criticando a forma como seus pares intelectuais estavam distanciados das práticas do mundo real. Porém, enquanto Marx (e, no caso, também Engels) utilizou tal situação para um estudo sobre a sucessão de sistemas de produção econômica, acarretando assim no estudo sobre dinâmica interna em um campo específico, Bourdieu trabalhou sobre a coexistência e interconexão de campos de produção científica e cultural.

Entretanto, o ponto que Burawoy mais destaca nessa suposta conversa entre Marx e Bourdieu é o fato de ambos trabalharem pelo desmascaramento da dominação, sendo que o primeiro destaca o caráter econômico, enquanto o segundo o faz com o caráter simbólico. Ambos, cada um em sua época, trabalham com a dominação que não é entendida como tal. Segundo Burawoy, Bourdieu vai mais além: supera a ideia de objetividade científica, defendendo que a sociologia que aplicamos a nossos objetos deve ser aplicada, "igualmente e justamente", a nós mesmos (idem, p. 26).

Apesar de tanto Marx quanto Bourdieu acreditarem que as ideias dominantes são as ideias da classe dominante, suas análises sobre dominação definem-se, dentre outras coisas, com base no tratamento inicial que é dado ao conceito. Enquanto Bourdieu trata da dominação considerando a superestrutura, Marx atenta à estrutura, e essa diferença influencia - e muito - o caráter do termo. Assim, quando pensamos dominação em Bourdieu, vemos uma tentativa de avançar no conceito de luta de classes marxista, a fim de refletir acerca de suas causas e consequências simbólicas. Logo, a luta de classes, expandindo-se do mundo econômico ao mundo da cultura, intenciona legitimar-se por meio da intermediação de estruturas simbólicas, com o finalidade de reproduzir as desigualdades entre as classes e naturalizar a dominação social. Assim Bourdieu vê uma estrutura de classes mais diversa que a marxista, mas concorda com Marx que estas são perpassadas por relações de dominação e exploração social. 
Por fim, vale lembrar que Bourdieu utiliza algumas ideias localizadas na teoria marxista, porém não travou nenhum diálogo mais consistente com ela, tratando de forma periférica alguns conceitos centrais para Marx, como o de exploração. Para Bourdieu, os diferentes tipos de capital são acumulados em lutas no campo e determinam a posição do agente nesse espaço, contudo, não trabalha o processo de exploração que pode nascer nesse processo.

\section{Bourdieu e Gramsci}

Aqui Burawoy passa a travar um possível diálogo entre Bourdieu e Gramsci. As análises sobre esses dois pensadores, mostrará Burawoy, têm evidentes semelhanças - inclusive pessoais -, e um dos motivos é que ambos trataram da superestrutura social. À primeira vista, ambos tratam o conceito de dominação e sua reprodução com termos semelhantes, porém, ao passo que o conceito bourdiesiano de violência simbólica pressupõe o desconhecimento da dominação enquanto tal, o conceito gramsciano de hegemonia implica o consentimento a esta. Em outras palavras, Bourdieu defende que os dominados nunca entenderiam as origens e condições de sua dominação, e por isso o senso comum seria sempre um senso ruim. E, ao contrário, Gramsci acredita que existe um fio de bom senso no senso comum da classe trabalhadora. De qualquer modo, em ambos aparece o papel do Estado nessa situação: enquanto para Gramsci o Estado organiza a hegemonia por meio das ligações existentes com a sociedade civil, para Bourdieu é esse Estado que detém o monopólio da violência simbólica legítima, que legitima as classificações existentes.

Para criticar o conceito gramsciano de intelectual orgânico, Bourdieu utiliza-se de sua ideia de classes populares como classes dominadas. De acordo com Gramsci, a verdade se encontrava em um diálogo constante entre o saber dos intelectuais e o bom senso dos operários, demonstrando assim o intelectual orgânico como um "companheiro" da classe trabalhadora. Este deveria elaborar o bom senso geral com base no senso comum trabalhador, a fim de formar um conhecimento teórico do mundo. Segundo Gramsci, esse intelectual deveria estar imerso em uma classe e ser vinculado a um partido político. Bourdieu, ironicamente, fala em "a mitologia do intelectual orgânico", pois defende que 
alguém fora da classe operária só conseguiria desenvolver uma identificação ilusória com esta, pois teria um habitus diferente, próprio da classe de sua origem individual. E essa diferença de habitus poderia acarretar num despotismo esclarecido, correndo-se o risco desses intelectuais manipularem os trabalhadores. Além disso, manter-se extremamente ligado a qualquer classe poderia contaminar o saber científico com valores desse campo. Em suma, Bourdieu acredita que a verdade estaria fundada apenas no bom senso dos intelectuais, transparecendo assim um Bourdieu conservador.

Ambos os autores repudiam o determinismo histórico de Marx e aprofundam o conceito de luta de classes, priorizando os efeitos da economia em vez de tratar apenas desse campo. No entanto, existem diferenças entre eles: enquanto um fundamenta a verdade na academia, outro o faz na experiência dos trabalhadores, e isso influencia suas visões sobre o papel e a importância da sociologia.

\section{Bourdieu e Burawoy}

Será na esteira da comparação entre Gramsci e Bourdieu que Burawoy dará inicio ao diálogo de sua própria obra com a do sociólogo francês. 0 grande tema deste terceiro diálogo será a consciência dos trabalhadores. Por um lado, mostra Burawoy, temos a teoria gramsciana da hegemonia, que dá margem à figura do intelectual orgânico que elaboraria o bom senso dos trabalhadores. Por outro lado, temos a teoria bourdiesiana da violência simbólica, segundo a qual não haveria bom senso a ser elaborado. Para Burawoy, Bourdieu oferece poucas evidências empíricas sobre a profundidade da violência simbólica, ao passo que o conceito gramsciano de hegemonia não explica a durabilidade da dominação capitalista.

Na tentativa de transcender a ambas perspectivas, Burawoy usará sua ideia de fabricação do consentimento. Segundo ele, existem certas estruturas e instituições no mundo do trabalho que fariam com que os trabalhadores cooperassem com a reprodução do capitalismo. Assim sendo, não havia apenas um consentimento desmistificado à dominação e nem esta seria fruto apenas de um habitus enraizado adquirido pela classe trabalhadora através de um processo de 
socialização. Aqui verifica-se uma explicação consensual ao debate Bourdieu versus Gramsci.

\section{Bourdieu e Fanon}

No quarto capítulo, os trabalhos de Bourdieu realizados na Argélia serão postos em diálogo com os que Fantz Fanon desenvolveu naquele país. Burawoy inicia o encontro entre esses dois autores mais uma vez valendo-se da comparação de dados biográficos, nas diferentes imersões de cada um dos autores no contexto colonial argelino.

Ambos os autores tiveram amargas experiências de marginalização na França: no caso de Bourdieu com base na classe, que é aludido em seu Esboço de autoanálise; já Fanon com base na raça, que é exposto em seu célebre trabalho Pele negra, máscaras brancas. Portanto, eles estavam bem equipados para reconhecer as abomináveis exclusões e opressões que jaziam na essência do colonialismo - muito embora suas origens étnicas e nacionais fossem colocá-los em posições bastante diferentes na ordem colonial argelina.

Ao passar da biografia à teoria, Burawoy encontra convergências referentes ao que Bourdieu e Fanon escreveram acerca do colonialismo e sua capitulação. Em primeiro lugar, ambos veem o colonialismo como um sistema violento, que não refere-se apenas à dominação, mas à segregação. As divergências, entretanto, não tardam a aparecer. Burawoy mostra que Bourdieu aproxima-se mais de um marxismo ortodoxo, ao defender que a classe trabalhadora era a classe eminentemente revolucionária. Por sua vez, Fanon argumenta que esse papel cabe ao campesinato.

Burawoy ainda desenvolverá neste capítulo uma crítica ao modo hostil com que Bourdieu se refere ao pensamento de Fanon sobre a situação pós-colonial africana e à ideia de intelectual orgânico.

\section{Bourdieu e Beauvoir}

Para o diálogo entre Bourdieu e Beauvoir, Burawoy se valerá da comparação entre $O$ segundo sexo, de Beauvoir, com A dominação masculina, de Bourdieu. Logo de início, Burawoy já nos apresenta um paradoxo: nas poucas oportunidades que 
Bourdieu faz menção à Beauvoir, ele o faz para caracterizá-la como vítima da violência simbólica, por se submeter às influência de Sartre, seu cônjuge. Burawoy argumentará ainda que além do silenciamento, Bourdieu ainda teria se valido de muitas das ideias já tratadas muitos anos antes por Beauvoir, tratando residualmente o que ela já tinha tratado minuciosamente. 0 grande mérito de Burawoy nesse diálogo é tentar explicitar esses pontos de convergência e demonstrar a "pálida reprise" que Bourdieu fez dos escritos de Beauvoir.

Uma dessas convergências, por exemplo, é no que diz respeito ao processo de emancipação das mulheres. Burawoy dirá que ambos trabalham com a ideia de "reconhecimento" para tratar da emancipação, entretanto, existe uma diferença de ênfase. Enquanto em Beauvoir a ideia de emancipação sempre está presente, Bourdieu trata disso como uma espécie de apêndice de sua obra. Nesse ponto, é interessante notar que Burawoy não faz apenas uma comparação dos argumentos de Bourdieu e Beauvoir, mas também de como, quando e em que medida esses argumentos aparecem no texto.

A já citada preocupação de Burawoy com a oposição entre teoria e prática não deixa de estar presente também neste capítulo. Aqui, Burawoy coloca tanto Bourdieu quanto Beauvoir em posição oposta a Fanon, no que diz respeito à defesa ao engajamento dos intelectuais na ação revolucionária. Diferentemente do que Fanon fez com relação às lutas anticoloniais, aponta Burawoy, Beauvoir demorou para ingressar no movimento feminista por acreditar que a questão das mulheres estava subordinada ao projeto socialista, mostrando assim que tanto Bourdieu quanto Beauvoir foram intelectuais tradicionais, se recusando a sair do papel do pesquisador.

\section{Bourdieu e Wright Mills}

É o único capítulo em que o verbo utilizado no título é "herdar", e não "encontrar", como nos restantes. Isso ocorre porque o livro se propõe a realizar supostos encontros, imaginados por Burawoy, entre Bourdieu e autores que este criticou. No caso de Mills, essa "retratação" seria desnecessária, dado que Bourdieu nunca foi hostil a Mills. Aliás, segundo Burawoy, Mills foi o "Bourdieu 
estadunidense", até porque Mills foi um dos poucos sociólogos estadunidenses que escaparam das críticas bourdiesianas à sociologia produzida nos Estados Unidos.

Nesse suposto diálogo, Burawoy demonstra que Mills e Bourdieu são claramente influenciados por Weber, pois ambos os autores demonstram preocupação com a dominação e suas consequências e características, não demonstrando grandes esperanças com utopias futuras. Quanto às suas respectivas teorizações sobre dominação, ambos são céticos sobre o conceito gramsciano de intelectual orgânico, acreditando apenas no intelectual independente. Também como semelhança pode-se citar a crítica de ambos aos tecnocratas e especialistas, pois estes seriam apenas servos do poder.

Assim como Bourdieu, Mills também tinha relações ambíguas com o marxismo. Ambos tomaram empréstimos da teoria marxista, mas nenhum deles utilizava as ideias de Marx como objeto constante de interlocução. Apesar disso, ambos trabalham com um conceito marxista central, que é o de classe. Nota-se que há semelhanças quanto às divisões de classe que estes autores utilizaram para trabalhar a forma como os dominantes impõem suas vontades ao restante da sociedade. Mills definiu três classes: uma coesa elite econômico-político-militar, uma nova classe média aburguesada e instável, e uma classe trabalhadora. E são exatamente essas classes que Bourdieu trabalha em seu livro $A$ distinção. Além dessas conceituações de classes, ambos veem com descrença o papel das lideranças dos trabalhadores, defendendo que, na realidade, estes apenas manipulam seus liderados para angariar suas vontades, que não seriam necessariamente a vontade dos trabalhadores.

Ambos tinham um engajamento político tradicional, distantes dos agentes. Apesar desse engajamento mais distanciado, no fim da vida, ambos publicaram trabalhos polêmicos e acessíveis, sendo que Bourdieu criticou o neoliberalismo e, Wright Mills, o imperialismo e a Guerra Fria.

\section{Considerações finais}

Valendo-nos dos escritos que Rui Braga, docente do departamento de sociologia da USP, fez para a apresentação à edição brasileira de $O$ marxismo encontra Bourdieu, podemos afirmar que o marxismo necessita sempre de 
aperfeiçoamentos e testes para ser, de fato, uma teoria social científica. Nesse sentido, a presente obra de Burawoy representa um grande benefício ao marxismo, por comparar minuciosa e criticamente, aspectos polêmicos da teoria marxista contemporânea com a obra de um dos autores mais críticos a essa teoria: Pierre Bourdieu, autor cuja obra foi por diversas vezes criticada por Burawoy. É instigante ler um livro com uma proposta tão ousada e original.

Burawoy endossa uma crítica que permeia todos os seus diálogos imaginários, a saber, o pouco crédito que Bourdieu dedicava em seus escritos aos seus antagonistas, valendo-se, segundo Burawoy, de "táticas de distinção pelas quais alguém silencia seu inimigo, torna-o invisível e, quando isso não é possível, transforma o antagonista em seu outro sem valor e indigno de atenção" (idem, p. 132). Verifica-se aqui como conceitos bourdiesianos de campo, trajetória, técnicas de distinção etc. estão intermitentemente implícitas em todos os supostos diálogos e, principalmente, nas relações engendradas por Bourdieu na vida real.

Assim, caminhando por terreno pedregoso, mas não por isso menos sedutor, Burawoy fez o marxismo encontrar Bourdieu. 0 que nos resta agora é encontrarmo-nos com mais esta obra de Michael Burawoy.

\section{Referências}

BourdieU, P. (1996). Razões práticas: sobre a teoria da ação. Editora Papirus, Campinas.

BuRAWOY, M. (2009). O marxismo encontra Bourdieu. Editora UNICAMP, Campinas.

MiCELI, S. (2003). "Bourdieu e a renovação da sociologia contemporânea da cultura”. Tempo social, São Paulo, vol. 15 n. 1, abr.

PASSIANI, E. (2006). "Imposturas intelectuais: a sociologia (auto)crítica de Pierre Bourdieu. Novos estudos CEBRAP, São Paulo, n. 74, mar.

Quiniou, Y. (2000). "Das classes à ideologia: determinismo, materialismo e emancipação na obra de Pierre Bourdieu”. Revista Crítica marxista, n. 11.

Recebido em março/2011

Aprovado em maio/2011 